\section{Commentary: Unusual lung transplant anastomotic techniques with a historical context}

\author{
James K. Kirklin, MD
}

Yokoyama and colleagues ${ }^{1}$ have provided a useful communication on unusual anastomotic solutions to pulmonary artery size discrepancy in lung transplantation. Whereas the vast majority of cases involve living lobar lung transplantation, the described techniques provide additional tools in the surgical approach to severe forms of size difference.

In many respects, the art of surgical suturing seems rather mundane in today's world of complex cardiothoracic surgery; but of course that wasn't always the case. When reviewing the history of vascular surgery and organ transplantation, we are reminded of the seminal work of Alexis Carrel, a French experimental surgeon who pioneered techniques of vascular anastomoses and later perfusion of organs for transplantation. His devotion to experimental surgery was apparently inspired by a political assassination. French President Sadi Carnot was fatally stabbed in the abdomen in 1894, when Carrel was a 21year-old surgeon-in-training. The stab wound resulted in laceration of the portal vein, producing uncontrolled and fatal bleeding. Surgeons of the time considered the injury irreparable. Deeply moved by this tragedy, Carrel dedicated his career to experimental surgery. In 1903 he emigrated from France to the United States, where he received a research appointment at the University of Chicago. Carrel

\footnotetext{
From the Division of Cardiothoracic Surgery, Kirklin Institute for Research in Surgical Outcomes, and Department of Surgery, University of Alabama at Birmingham, Birmingham, Ala.

Disclosures: Dr Kirklin receives partial salary support paid to his institution for his role as director of the Data and Clinical Coordinating Center for the Society of Thoracic Surgeons Intermacs Database.

The Journal policy requires editors and reviewers to disclose conflicts of interest and to decline handling or reviewing manuscripts for which they may have a conflict of interest. The editors and reviewers of this article have no conflicts of interest.

Received for publication June 18, 2021; revisions received June 18, 2021; accepted for publication June 28, 2021; available ahead of print July 1, 2021.

Address for reprints: James K. Kirklin, MD, Division of Cardiothoracic Surgery, Kirklin Institute for Research in Surgical Outcomes, and Department of Surgery, University of Alabama at Birmingham, ZRB 739, 703 19th St, S, Birmingham, AL 35294 (E-mail: jkirklin@uabmc.edu).

JTCVS Techniques 2021;9:195-6

2666-2507

Copyright (c) 2021 The Author(s). Published by Elsevier Inc. on behalf of The American Association for Thoracic Surgery. This is an open access article under the CC BY-NC-ND license (http://creativecommons.org/licenses/by-nc-nd/4.0/). https://doi.org/10.1016/j.xjtc.2021.06.039
}

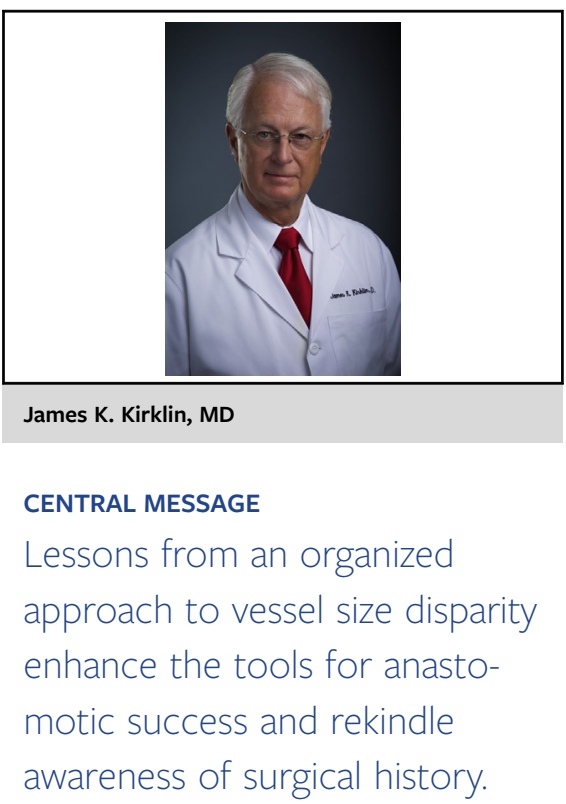

began a collaboration with Charles Guthrie in experiments on vascular suturing techniques. He relocated to New York in 1906 and began working at the Rockefeller Institute of Medical Research, where he spent the remainder of his career. In 1912, he was awarded the Nobel Prize in Physiology or Medicine for pioneering techniques of vascular anastomoses. He continued to make important scientific contributions despite gaining notoriety for his controversial political and social ideas, which he shared with Charles Lindbergh. They became kindred spirits and collaborated scientifically to build the first organ perfusion pump, an invention that helped pave the way for future transplantation.

Lung transplantation today is routine, and the authors have provided guidance for specific unusual circumstances. But perhaps the real value of this piece is to stimulate us to refocus on the importance of perfection in our anastomotic techniques, whether it be the bronchial, pulmonary artery, or pulmonary vein lung transplant anastomosis; a small caval or pulmonary anastomosis in an infant heart transplant; neonatal cardiac reconstructions; or coronary revascularization. Technical details are the sine qua non of good long-term outcomes that depend on unrestricted flow in a limited space. The challenge is magnified when there is a vessel size discrepancy or length issue in the anastomotic space; the surgeon must place accurate sutures, which accommodate circumferential disparity, minimize endothelial trauma, and avoid the redundancy that promotes angulation or kinking. The 
authors have channeled their own experience into an organized set of techniques for lung transplant surgeons to add to their active armamentarium.

\section{Reference}

1. Yokoyama Y, Chen-Yoshikawa TF, Nakajima D, Ohsumi A, Date H. Various techniques for anastomosis of pulmonary arteries with size mismatch during lung transplantation. J Thorac Cardiovasc Surg Tech. 2021;9:192-4. 